\title{
Esta es mi cara y esta es mi alma
}

\author{
Andrés Soria Olmedo \\ Universidad de Granada
}

Título: Esta es mi cara y esta es mi alma.

Resumen: El presente trabajo comenta cuatro autorretratos en verso de Manuel Machado: "Adelfos", de Alma (1902), y "Retrato", "Prólogo-epílogo" y "Yo, poeta decadente...", de El mal poema (1909), centrándose en la intertextualidad y/o en la memoria poética. En ellos, las alusiones integrativas -que se armonizan en una voz nueva- y las alusiones reflexivas -donde la voz que imita y la imitada continúan cada cual en su mundo- contribuyen a oponerse a la ideología de un yo transparente e instalan estos poemas en el espacio europeo y americano del decadentismo modernista.

Palabras clave: Manuel Machado, autorretrato poético, Modernismo, Decadentismo.

Fecha de recepción: 20/7/2015.

Fecha de aceptación: 16/10/2015.
Title: This is my Face and this is my Soul.

Abstract: This essay offers some comments on four self-portraits in verse by Manuel Machado: "Adelfos", from Alma (1902), and "Retrato", "Prólogo-epílogo" and "Yo, poeta decadente...", from El mal poema (1909), drawing upon intertextuality and/or poetic memory. In them, integrative allusions -which harmonize in a new voice- and reflective allusions -in which both voices, imitating and imitated, remain in separate worlds- contribute to resist the ideology of a translucent ego, and to install these poems into the european and american space of decadence.

Key words: Manuel Machado, Poetic Selfportrait, Modernism, Decadence.

Date of Receipt: 20/7/2015.

Date of Approval: 16/10/2015.

La seducción del título, tan prometedor, me volvió ciego a la osadía del empeño, sobre todo estando entre nosotros Rafael Alarcón. Pero no hay vuelta atrás. Bien agarrado de su mano, propongo algunos comentarios a cuatro autorretratos en verso de Manuel Machado, muy conocidos por otra parte: "Adelfos" abre el poemario Alma (1902), y en El mal poema 
(1909), "Retrato", "Prólogo-epílogo" y "Yo, poeta decadente..." son los tres primeros con que el lector se encuentra ${ }^{1}$.

Puesto que el procedimiento poético de Machado "es el de reescribir y adaptar el mayor número posible de topoi y recursos pertenecientes a las distintas tradiciones líricas que conjuga" ${ }^{2}$, me fijaré sobre todo en algunos de estos intertextos, leyendo en voz alta algunas de las notas que en las buenas ediciones -como la que cito- instauran un diálogo tácito con el lector, con la pretensión de que al glosarlos aparezcan más voces en cada voz, un horizonte de lectura más amplio y más complejo.

En el plano general de la intertextualidad Cesare Segre recordó que, a juicio de Bajtín, el sacar a la luz las influencias consiste en el desvelamiento de una vida semiescondida de la palabra ajena en un contexto nuevo; cuando estamos ante un influjo profundo y productivo no hay una imitación exterior o una simple reproducción, sino un desarrollo creativo ulterior de la palabra ajena (o más exactamente, semiajena) en un contexto nuevo, en nuevas condiciones ${ }^{3}$; y eso tanto en las relaciones entre textos propiamente dichos como en la "interdiscursividad" relativa a las relaciones que cada texto mantiene con los discursos de cada cultura o ideología. A pesar de que Bajtín excluye la poesía de la pluridiscursividad (nunca empleó el término “intertextualidad”), la alusividad es un modo de diálogo entre poetas ${ }^{4}$, mediante el cual se enriquecen y desestabilizan

1 Dejamos fuera el "Nuevo auto-retrato" publicado en $A B C$ en 1925, luego recogido en Phoenix (1936) y más separado del eje finisecular, aunque en él resuena una dimensión retrospectiva que no está en los otros: "Mi propia obra es sólo una polifonía [...] de gritos de mi tiempo [...] Oí la voz de todo [...] y mientras escuchaba la completa sonata, / pasó la vida a un lado como una cabalgata". Véase la tesis doctoral de Vicente Sabido, dirigida por Miguel d'Ors: Manuel Machado. Phoenix. Nuevas canciones. Edición, prólogo y notas, Granada, Universidad, 1981, p. 232. Efectivamente, según Allen W. Phillips, "Poetas del día. "El Liberal»" 1908-1909, Madrid, Anthropos, 1989, p. 42, los alejandrinos tienen una "tonalidad grave" parecida a la de su hermano Antonio.

2 Rafael Alarcón Sierra, "Introducción" a Manuel Machado, Alma, Caprichos, El mal poema, ed. Rafael Alarcón Sierra, Madrid, Castalia, 2000, p. 73.

3 Cesare Segre, "Intertestualità e interdiscorsività nel romanzo e nella poesia", en Teatro e romanzo, Turín, Einaudi, 1984, pp. 103-118 (p. 105). El texto está en Mijail Bachtin, "La parola nel romanzo", en Estetica e romanzo, Turín, Einaudi, 1979, p. 155.

4 Cesare Segre, op. cit., p. 113. 
felizmente las relaciones entre el pasado y el presente, entre lo "nacional" y lo "extranjero", entre lo que llamamos "literatura" y lo que llamamos "vida". La memoria poética ${ }^{5}$ se ha mostrado en dos formas principales: la alusión integrativa, donde las dos voces se funden como en los términos de una metáfora, y la reflexiva, donde las dos voces se acercan y se comparan como en una metonimia. En el primer tipo de memoria hay una especie de orquestación o fusión, en el segundo de contraposición o contrapunto ${ }^{6}$.

Así, las alusiones encierran armónicos y resonancias, como en un acorde musical con el que se disfruta cuando se recuerda; a su vez, todo recuerdo es histórico, queda ordenado por una franja ideológica subordinada al presente. El espacio ideológico en el que se alojan estos autorretratos es la estructura diacrónica abierta por el Romanticismo. Cuando el poema dejó de ser considerado como el reflejo de un espejo sobre el mundo para pensarse como una lámpara que ilumina desde dentro el interior del sujeto, se convirtió, como el corazón de Poe, en un delator del artista, aunque sea un delator "ambiguo" 7 , no transparente, sino filtrado por la máscara del héroe desde que Chateaubriand, a través de su René y su amplificación de las Memorias de ultratumba, abriera el camino a una literatura que asigna al escritor el papel de un orador sagrado sin Dios, situado en una tierra de nadie donde la infinitud del deseo se encuentra con la finitud de las cosas, cuyo eco se prolonga en el Des Esseintes de $\grave{A}$ rebours de Huysmans (1884) y en otros personajes del fin de siglo XIX y comienzos del $\mathrm{XX}^{8}$, dandies, malditos, decadentes. La decadencia es una de las facetas de la modernidad, y Huysmans, se ha dicho, "totally equates modernity-artificiality-decadence"'.

5 Gian Biagio Conte, Memoria dei poeti e sistema letterario. Catullo, Virgilio, Ovidio, Lucano, prefazione di Cesare Segre, Palermo, Sellerio, 2012.

6 Ezio Raimondi, Le metamorfosi della parola, da Dante a Montale, Milán, Bruno Mondadori, 2004, p. 111.

7 Rafael Alarcón Sierra, Entre el modernismo y la modernidad: la poesía de Manuel Machado (Alma y Caprichos), Sevilla, Diputación, 1999, p. 132, cita con pertinencia el ensayo clásico El espejo y la lámpara (1953) de M. H. Abrams.

8 Ezio Raimondi, “Tra d'Annunzio el il Novecento", en Un europeo di provincia: Renato Serra, Bolonia, Il Mulino, 1993, p. 179, parafraseando, sin citar el nombre de su amigo, el prólogo de Marc Fumaroli a la novela de Huysmans.

9 Matei Calinescu, Five Faces of Modernity: Modernism, Avant-Garde, Decadence, 
En 1940 Manuel Machado evocó los últimos meses de 1900 en París, cuando comenzaba Alma: "Lo que yo escribo ahora [...] soy yo, mi propia alma. Y me digo todo, tal como era entonces, en unos versos que se titulan "Adelfos", nunca he sabido por qué" ${ }^{10}$. Inmediatamente viene a la memoria el comienzo de las confesiones de Rousseau: "Je veux montrer à mes semblables un homme dans toute la vérité de la nature: et cet homme ce sera moi". Y enseguida aprendemos ya en el propio Rousseau que la palabra de la autenticidad permite deformar e inventar, con tal de producir su verdad ${ }^{11}$. La transparencia es engañosa. Rafael Alarcón ha repasado con extraordinaria minucia las interpretaciones del poema en clave biográfica, en virtud de las cuales el autor era un "señoritingo andaluz" (Moreno Villa) y el poema una "sublimación del señorito" (Max Aub), "su primer retrato completo, definitivo, acabado" (Gerardo Diego) ${ }^{12}$; para el Salinas de 1938 -cuando presentaba modernismo y 98 como "un conflicto entre dos espíritus" - el poema era muestra de "derrotismo espiritual enmascarado de exquisitez literaria" ${ }^{13}$, mientras que para Dámaso presentaba "un tema medular de la generación del 98: el de la voluntad"14.

Sin embargo, aun declinado en términos de abulia noventayochista (que es también schopenhaueriana): "Mi voluntad se ha muerto una noche de luna / en que era muy hermoso no pensar ni querer..."), "Adelfos" se instala en el espacio europeo del decadentismo, a partir de los versos verlainianos que se convirtieron en el emblema de esa idea y adquirieron valor de manifiesto ${ }^{15}$ :

Je suis l'Empire à la fin de la décadence

Qui regarde passer les grandes Barbares blancs

Kitsch, Postmodernism, Durham, Duke University Press, p. 172.

10 Rafael Alarcón Sierra, op. cit., p. 48.

11 Jean Starobinski, Jean-Jacques Rousseau. La transparencia y el obstáculo, Madrid, Taurus, 1983, p. 245.

12 Rafael Alarcón Sierra, op. cit., p. 137.

13 Ibidem, p. 153.

14 Ibidem, p. 153. Remito por último a Dámaso Alonso, Obras completas IV. Estudios y ensayos sobre literatura. Tercera parte. Ensayos sobre literatura contemporánea, Madrid, Gredos, 1975, p. 585.

15 Matei Calinescu, op. cit., p. 171. Véase asimismo Gillian Gayton, Manuel Machado y los poetas simbolistas franceses, Valencia, Bello, 1975, p. 54. 
En composant des achrostiques indolents

D'un style d'or dont la langueur du soleil danse...

“Langueur” (incluido en Jadis et Naguère, 1884).

Escribe Machado:

Yo soy como las gentes que a mi tierra vinieron -soy de la raza mora, vieja amiga del Sol-, que todo lo ganaron y todo lo perdieron. Tengo el alma de nardo del árabe español.

En una reseña de Alma publicada en El Heraldo de Madrid por Unamuno, el implacable enemigo de la "música exterior" de los modernistas admitía la genealogía cultural de ese fin de raza, ofreciendo de paso una pequeña teoría de la intertextualidad:

la raza mora de este Machado es una raza mora que se ha bautizado en París y ha oído a Musset y a Verlaine, y en algunos de sus cantos hay dejos fatales de Leconte de Lisle, como en su Oasis, y de José María de Heredia, como en sus Flores. ¿Y qué? Todos nos buscamos a través de los demás, y no hay otro modo de llegar a encontrarse. Y él canta su canto, y hasta cuando las palabras sean de otros, es la música suya. Y muchas veces de su música surge su letra, la suya ${ }^{16}$.

Para la siguiente estrofa se ha recordado a Verlaine ("Votre âme est un paysage choisi") ${ }^{17}$ y la flor azul del Heinrich von Ofterdingen de Novalis; podríamos añadir un paso de Il piacere de d'Annunzio: cuando se conocen Andrea Sperelli y Elena Muti, en la mesa hay una orquídea: "Flor diabólica", dice ella; "Flor simbólica, entre sus dedos, murmuró Andrea, mirando a la dama, a la que aquel gesto era admirable en extremo" ${ }^{18}$. He aquí los versos de Machado:

En mi alma, hermana de la tarde, no hay contornos... y la rosa simbólica de mi única pasión es una flor que nace en tierras ignoradas y

16 Rafael Alarcón Sierra, op. cit., p. 64.

17 Gillian Gayton, op. cit., p. 43; y Rafael Alarcón Sierra, op. cit., p. 159.

18 Gabriele d’Annunzio, El placer, ed. Rosario Scrimieri, Madrid, Cátedra, 1991, p. 131. 
que no tiene aroma, ni forma, ni color.

Por otro lado, la célebre frase del Journal intime de Amiel (1884), "Un paysage est un état d'âme", comentada por Brunetière en Symbolistes et décadents (1888), un combativo escrito contra los naturalistas, sitúa el decadentismo como antesala del simbolismo:

Cela ne veut pas dire qu'un paysage change d'aspect avec l'état de l'âme [...] cela veut dire qu'entre la nature et nous il y a des correspondances, des affinités latentes, des identités mystérieuses, et que ce n'est qu'autant que nous les saisissons que, pénétrant de l'intérieur des choses, nous en pouvons vraiment approcher l'âme. Voilà le principe du Symbolisme ${ }^{19}$.

Las siguientes estrofas de "Adelfos" amplifican la actitud "blasée" del dandy, receptor indiferente en lo erótico y lo artístico ("Besos, ¡pero no darlos! Gloria... ¡la que me deben! [...] Un vago afán de arte tuve... Ya lo he perdido / Ni el vicio me seduce, ni adoro la virtud").

Por supuesto, el dandy ("Le dandysme: un culte de la différence dans le siècle de l'uniforme. Et une dénonciation") ${ }^{20}$ es aristócrata: "No se ganan, se heredan elegancia y blasón...", aunque irónico: "Pero el lema de casa, el mote del escudo, / es una nube vaga que eclipsa un vano sol".

En suma, los intertextos estructuran el confesionalismo del autorretrato y dejan ver con mayor claridad la paradoja de que lo natural es "una legalidad" 21 .

Los tres siguientes autorretratos, incluidos esta vez en El mal poema (1909), cuentan ya con "Adelfos" como intertexto, gracias al cual ese tipo de poemas se convirtió con rapidez en un subgénero plagado de tópicos ${ }^{22}$.

19 Gabriele d'Annunzio, Il Piacere, con apparati informativi di Anna Maria Andreoli, Milán, Mondadori, 2013, edición digital, pos. 5974 de 9388: 63 (consultada el 20/11/2015).

20 Roger Kempf, Dandies. Baudelaire \& Co., París, Seuil, 1977, p. 9.

21 "L'illusion de naturel est sans cesse dénoncée... Le naturel n'est nullement un attribut de la Nature physique; c'est l'alibi dont se pare une majorité sociale: le naturel est une légalité. D'où la nécessité critique de faire apparaître la loi sous ce naturel-là" (Roland Barthes, Roland Barthes par Roland Barthes, Paris, Seuil, 1975, p. 134).

22 Rafael Alarcón Sierra, El mal poema de Manuel Machado. Una lírica moderna y dia- 
El título El malpoema se relaciona con Les fleurs du mal², y quizá como antítesis con La bonne chanson de Verlaine ${ }^{24}$, pero conserva una ambigüedad irónica que le permite acercarse a la realidad viva y cotidiana mezclando una pluralidad heterogénea de estilos y voces. Alarcón ha podido acudir a lo que Bajtín llamaba el espacio de lo cómico-serio para exponer en qué términos El mal poema pone en juego "una profunda transgresión, una fuerte ironía, un tono criticista y un talante dialógico" 25 .

Consciente del potencial transgresor del libro, Machado se justificó mediante una "autocrítica" en forma de carta abierta dirigida a Juan Ramón Jiménez (luego incluida en La guerra literaria (1913):

Habrás recibido El mal poema, por el que te suplico que no me quieras del todo mal. Conozco la delicadeza de tu espíritu y sé que te chocan ciertas trivialidades y malsonancias de que por desgracia está lleno nuestro vivir. Pero creo haberte dicho en mi descargo que, no sólo se canta lo que se ama, sino lo que se odia más cordialmente. En suma, todo lo que de veras nos impresiona ${ }^{26}$.

"Te chocan". El uso de ese neologismo, tan flagrante en 1903, se presta a especular con la observación que hizo Walter Benjamin treinta años más tarde de que la poesía lírica (de Baudelaire y a partir de él de la lírica moderna) se fundamenta en una experiencia en la cual la vivencia del shock se ha convertido en norma ${ }^{27}$. Se puede aplicar a El mal poema, cuyo

lógica, Madrid, Biblioteca Nueva, 2008, p. 73.

23 Allen W. Phillips, "Decadents Elements in the Poetry of Manuel Machado", en Waiting for Pegasus. Studies of the Presence of Symbolism and Decadence in Spanish Letters, Roland Grass y William. R. Risley, Macomb (Illinois), Western Illinois University, 1979, pp. 65-76 (p. 68).

24 Gilliam Gayton, op. cit., p. 128.

25 Rafael Alarcón Sierra, "Introducción” a Manuel Machado, op. cit., p. 57.

26 Rafael Alarcón, El mal poema, p. 46.

27 Walter Benjamin, "Die Frage meldet sich an, wie lyrische Dichtung in einer Erfahrung fundierte sein könnte, der das Chocerlebnis zur Norm geworden ist", en Illuminationen. Ausgewählte Schriften 1, Frankfurt, Suhrkamp, 1977, p. 192. En la traducción de Jesús Aguirre el término se transcribe con una grafía germanizada y menos clara que en el original, donde se conserva la forma francesa ("Choc") de donde procede también el neologismo machadiano: "Apunta la pregunta acerca de cómo pueda fundarse la poesía lírica en una experiencia para la cual la vivencia del schock se ha convertido en 
autor reconoce, en la citada carta, aunque no comparezca el nombre: "Los talentos poéticos que más me asimilo son Poe, Heine, Verlaine, nuestro Bécquer, aventureros del ideal a través de las pasiones amargas y de la vida rota".

Por otro lado, en 1940 ("Unos versos, un alma y una época”) entonó una vehemente palinodia, concediéndole al libro una transparencia que éste nunca quiso tener: ("Siento hoy casi vergüenza de este libro en que se desnuda en público un alma lamentable y pecadora") ${ }^{28}$, ya que el punto de partida era ya una máscara, la del autorretrato del libro Alma, y los sucesivos intentos de arrancársela fueron también ejercicios de noidentidad: "M. Machado jamás logró retratarse a sí mismo. O quizás sí: Porque quizá sea en esa heterogeneidad no-significativa donde radique su riqueza" 29 .

"Retrato" apareció en la sección "Poetas del día" de El Liberal el 25 febrero 1908, con un retrato fotográfico, formando parte de "una galería de autopinturas poéticas" de distinto calibre (Valle-Inclán, Martínez Sierra, Emilio Carrere, Santos Chocano), entre otras la de su hermano Antonio ${ }^{30}$.

Ya el primer verso "Esta es mi cara y esta es mi alma. Leed" nos instala en la imposibilidad de decidir si hay que dar por consabida la relación especular o analógica entre la cara y el alma. ¿Tiene el yo un alma o interior y es transparente? ¿Puede inferirse ese interior de lo aparente? Los anglosajones victorianos creían que sí, hasta que los pintores prerrafaelitas y los poetas desde Browning en adelante empezaron a desconfiar. El crítico e historiador del arte Michael Fried estudió cómo Manet empezó a concentrarse en la superficie pintada a expensas de la ilusión de profundidad, marcada por lo que llama "absorción”. El espectador de estos cuadros entra en contacto con la intimidad de los personajes pintados y se olvida de que está ante un lienzo. En cambio, lo que llama pintura "teatral" tiende

norma”. Véase Walter Benjamin, Iluminaciones/2, Madrid, Taurus, 1972, p. 131.

28 Allew W. Phillips, "Decadent", p. 76.

29 Juan Carlos Rodríguez, "Manuel Machado: una poética de la no-identidad", en De qué hablamos cuando hablamos de literatura, Granada, Comares, 2002, p. 475.

30 Allen W. Phillips, Poetas; María A. Salgado, "Galería de autosemblanzas de El Liberal", en Actas de la Asociación Internacional de Hispanistas, IX, Frankfurt am Main, Vervuert, 1989, pp. 389-395. 
a que el espectador no olvide que está mirando una pintura. El retrato literario se mueve en la misma dirección ${ }^{31}$, y en éste se ha buscado que aflore la heterogeneidad ${ }^{32}$.

Los rasgos físicos, por metonimia, se reducen a "unos ojos de hastío y una boca de sed... / Lo demás... Nada... Vida... Cosas... Lo que se sabe...”. Si la boca puede estar por el deseo, en ese hastío resuenan quizá los terribles versos del primer poema de Las flores del mal, "Au lecteur": "C'est l'Ennui! [...]. / Tu le connais, lecteur, ce monstre délicat. / -Hypocrite lecteur, -mon semblable-, mon frère!"33

"Lo demás" (el juego, la bebida, las mujeres) es voluntariamente vago, escaso, dejado en suspenso (“ ¿Vicios? Todos. Ninguno...”). La reticencia afecta incluso al gesto dandy de la "sprezzatura" ("Me acuso de no amar sino muy vagamente"), que no obstante pone "la agilidad, el tino, la gracia, la destreza," por encima de "la voluntad, la fuerza y la grandeza...". Como deshaciendo la supuesta naturalidad de "Adelfos", a la analogía sucede la ironía, a las "languideces de la luna" la risa y el sol, a la "alta aristocracia”, la elegancia "recherchée" de "lo chic y lo torero". Da una vuelta de tuerca a la base simbolista y acentúa el desgarro decadente, ostentándose como estereotipo: "Medio gitano y medio parisién -dice el vulgo-, / con Montmartre y con la Macarena comulgo...” (con análoga irreverencia su hermano Antonio escribirá más tarde de cierta España que es "Devota de Frascuelo y de María, / de espíritu burlón y de alma quieta"). "Y, antes que un tal poeta, mi deseo primero / hubiera sido ser un buen banderillero". Este último desplante no tiene tanto que ver con la fiesta nacional cuanto con la apología de la ligereza y la tradición moderna del artista como saltimbanqui, como acróbata:

Par sa virtuosité même, la prouesse acrobatique se sépare de la vie de ceux d'en bas: le poète, s'il en fait à lui- même l'application allégorique, se donne pour vocation d'affirmer sa liberté en un jeu supériur et gratuit, tout en faisant la grimace aux bourgeois, aux "assis" 34 .

31 Frances Dickey, The Modern Portrait Poem. From Dante Gabriel Rosetti to Ezra Pound, Charlottesville y Londres, University of Virginia Press, 2012.

32 Rafael Alarcón Sierra, El mal poema, p. 78.

33 Charles Baudelaire, Les fleurs du mal, ed. Claude Pichois, París, Gallimard, 1972, p. 32.

34 Jean Starobinski, Portrait de l'artiste en saltimbanque, Lausana, Skira, 1970, p. 35. Unos años más tarde, Cernuda escribirá un poema titulado "Vientres sentados". 
El brusco mutis final ("Es tarde... Voy de prisa por la vida. Y mi risa / es alegre, aunque no niego que llevo prisa) culmina la "irónica voladura de todo idealismo finisecular, plenamente asumido ya en el horizonte de expectativas de la época" 35 .

"Prólogo-epílogo" es como una segunda parte del anterior y casi una síntesis de todo el libro. El modelo confesional guarda analogías con el Rubén Darío de la "Epístola a la señora de Leopoldo Lugones" (1907) y el Villon que entusiasmó a todo el siglo XIX tras siglos de eclipse ${ }^{36}$ y que exaltara Des Esseintes poniéndolo al par del Verlaine de Sagesse, cuyos "cautivantes versos" le parecían "inspirados en la poesía dulce y transida de Villon"37 ("En l'an trentième de mon âge, / que toutes hontes j'ai les ai bues, / Ne du tout fol, ne du tout sage, / Non obstant maintes peines eues") $)^{38}$.

El carácter epilogal deriva de que este yo completamente teatralizado en el sentido explicado más arriba, convertido en estereotipo y por eso mismo problemático, cuenta que se retira de la poesía por prescripción facultativa: "[...] Renuncio, / pues, a ser un Verlaine, un Musset, un D’Annunzio / -¡no que no!-”. La expresión coloquial subraya la ironía de la emulación de los héroes estéticos, también despersonalizados por el artículo indeterminado.

"Ello es que se acabó... ¿Por siempre?... ¿Por ahora?”. No se resuelve a que el abandono sea definitivo, aunque sí a no regresar a un modo de poesía en el que los lectores "damas "y "galanes" que son otros tantos "Ineses y Donjuanes" apreciaron "la novedad de ciertas amables languideces [...] y la ágil propulsión de la vida [...] hacia el amor de la Belleza [...] alegre, y ni moral ni inmoral, a mi modo" ${ }^{39}$. El juicio depende de ellos ("Tal

35 Rafael Alarcón Sierra, El mal poema, p. 82.

36 Italo Siciliano, François Villon et les thèmes poétiques du Moyen Âge, Paris, Armand Colin, 1934. p. 528.

37 J. K. Huysmans, Contra natura, traducción y prólogo de Guillermo Cabrera Infante, Barcelona, Tusquets, 1980, p. 217.

38 Rafael Alarcón Sierra, El mal poema, p. 92, “Testamento": "Heme aquí llegado a mis treinta años / cuando ya he bebido tantos malos tragos; / mas no estoy muy loco, ni tampoco muy cuerdo, / después de pasar estos sufrimientos". Véase François Villon, Poesía, ed. de Juan Victorio, Madrid, Cátedra, 1985, p. 55.

39 Oscar Wilde, El retrato de Dorian Gray, trad. y notas de Ricardo Baeza, Madrid, Atenea, 1919, I, p. 5: "No hay libros morales ni inmorales. Los libros están bien o 
me dicen que fui para ellos. Y tal / debí de ser”). Con una construcción sintáctica como calcada del francés ("Nosotros nos conocemos mal / los artistas") renuncia a toda introspección.

La segunda estrofa atribuye el abandono al estado de la poesía en una tierra donde "la pobre Musa llora / por los rincones como una antigua querida / abandonada y ojerosa y mal ceñida, rodeada de cosas feas” que espantan la belleza. La posición es cercana a la de Unamuno en 1904, muy crítico con los jóvenes, aunque sin la ironía de este último: "El turrieburnismo, el encerrarse en la torre de marfil a sońar con princesas de cromo o a fantasear un helenismo traducido del francés me parece, en España, un pecado contra la humanidad" 40 .

Esos lujos serían permisibles en países más plenos de recursos; pero en España

ciertas pretendidas exquisiteces literarias o artísticas, mezquinos remedos de monsergas bulervaderas [sic] resultan collares de diamantes -americanos, por supuesto- o brazaletes de lujo en una pobre moza hambrienta, escuálida, sucia y andrajosa. Entran ganas de decirle: "ve, vende esos chismes, y luego come, lávate y cómprate un trajecillo de percal, limpio y barato" 41 .

De modo parecido, para Machado, "en un pobre país viejo y semisalvaje”, los ricos, caciques tremendos, no llegan al oro, sino que "apilan Himalayas de cobre” y están lejos de los clásicos Mecenas, Petronio, Lúculo ${ }^{42}$. Desrealizando una expresión coloquial, en consecuencia [...], el Arte, / mendigo, emigra con la música a otra parte" ${ }^{43}$. Es cierto, como advirtió Dámaso Alonso, que aquí Manuel Machado da "signos positivos de su oposición al clima espiritual de la España en que vive" ${ }^{44}$.

mal escritos. Simplemente".

40 Geoffrey Ribbans, Niebla y soledad, Madrid, Gredos, 1971, p. 49.

41 Geoffrey Ribbans, ibidem, p. 49.

42 Con sus respectivos artículos, "un Mecenas, un Lúculo, un Petronio".

43 La misma expresión se halla al final de la elegía "A José Nogales, muerto", poema del ciclo de El mal poema: “¡Valiente soldado del Arte, / adiós, que luego nos veremos!... / También nosotros pronto iremos / con nuestra música a otra parte" (Manuel Machado, Alma, p. 268).

44 Dámaso Alonso, op. cit., p. 585. 
La siguiente tirada comienza con una variación sobre el paso del tiempo ("Luego, la juventud que se va, que se ha ido") que hace pensar otra vez en Villon: "Je plaings le temps de ma jeunesse, [...] Il ne s'en est à pied allé, / N'a cheval; las! et comment donc? / Soudainement s'en est voilé", [...] ("Grand Testament", estrofa XXII) ${ }^{45}$ y continúa con un resumen de lo que Alarcón llama "contradictoria psicología femenina sub specie finisecularis" 46 ; un repertorio misógino y abstracto ("la mujer") de las cualidades de la "dulce enemiga" de linaje petrarquista, es decir: "La mujer -ideal y animal-, la que obliga / -gata y ángel- a ser feroz y tierno [...]. Pecadora, traidora, y santa y heroína, / que ama las nubes, y el dolor y la cocina". Estos versos se han relacionado con los de Verlaine: "O la femme! Prudent, sage, calme ennemi, / $N^{\prime}$ exagerant jamais ta victoire à demi... / ou bon ami... / Et doux, trop doux souvent" ${ }^{47}$, aunque la estima del dandy no es muy alta (Flaubert a Baudelaire, carta de 21 de octubre de 1857 para agradecerle la crítica de Madame Bovary: "La femme est naturelle, c'est à dire abominable” $)^{48}$.

"A mí no me fue mal. Amé y me amaron. Digo...", escribe Machado. Se apiadaron de él, alguna vez le permitieron la embriaguez erótica, aunque ya no es (a lo Góngora) "en el campo de plumas de Amor el gran soldado"; con lo que, "sabiendo por los padres del Concilio de Trento / lo que hay en ellas de alma, me he dado por contento" ${ }^{49}$.

Resumen: que razono mi adiós, se me figura

por quitarte a la sola palabra su amargura,

porque Espańa no puede mantener sus artistas,

porque ya no soy joven, aunque aún paso revistas,

45 "Yo lamento el tiempo de mi juventud [...]. Su marcha no ha sido a pie, paso a paso, I tampoco a caballo. ¿Pues cómo se fue? Se fue de repente, en rápido vuelo” (Manuel Machado, Alma, p. 62).

46 Rafael Alarcón Sierra, El mal poema, p. 102; Luisa Cotoner Cardó, " "Felina y angélica»: un acercamiento a la imagen de la mujer en Manuel Machado”, Ínsula, 608-609 (1997), pp. 22-29.

47 Paul Verlaine, "Lucien Létinois" III, de Amour. Véase Gilliam Gayton, op. cit., p. 132.

48 Roger Kempf, op. cit., p. 69.

49 Se ha señalado que se trata de un anacronismo. No fue en ese Concilio, sino en otro medieval en el que se decretó. 
y porque -ya lo dice el doctor-, porque, en suma, es mi sangre la que destila por mi pluma ${ }^{50}$.

La conclusión epiloga el epílogo (sin llegar a la coquetería de Espronceda: “Malditos treinta años, / funesta edad de amargos desengaños!” ${ }^{51}$ y el poema termina con una imagen ya empleada por escritores como Whitman, Ramón Gómez de la Serna ("El escritor es un mártir que sangra por la mano derecha”), Unamuno, Juan Ramón Jiménez y antes por Alfred de Musset ${ }^{52}$. En el poema "La nuit de mai" (1835), dialogan el Poeta y Musa. Cuando el Poeta decide: "La bouche garde le silence / Pour écouter parler le coeur", la Musa lo exhorta a no quedarse mudo, y le narra la historia del pelícano, que alimenta a sus hijos con su corazón ${ }^{53}$ ("Le sang coule à long flots de sa poitrine ouverte”), advirtiéndole que los grandes poetas, cuando hablan de olvido, de amor y de desgracia, hacen como los pelícanos y sirven en sus fiestas "festines humanos": "Leurs déclamations sont comme des épées; / Elles tracent dans l'air un cercle éblouissant; / Mais il y pend toujours quelque goutte de sang ${ }^{54}$.

En Machado la imagen es inquietante, porque aunque los poetas ya no declamen, sino todo lo contrario, a pesar del distanciamiento irónico, se escapa la unidad de vida y literatura.

"Yo, poeta decadente..." 55 se apoya también en el yo medieval de François Villon ("Mil quatre cens cinquante et six, / Je, François Villon, escollier, / Considérant, de sens rassis..." ${ }^{56}$ ), lo cual contribuye al máximo de teatralidad e ironía objetiva (como en una instancia administrativa: "Yo, poeta decadente español del siglo XX"), además de desplazar la figura del dandy hacia los márgenes de la bohemia ("las golfas y el aguar-

50 Manuel Machado, op. cit., p. 203-204.

51 José de Espronceda, El Diablo mundo, ed. Robert Marrast, Madrid, Castalia, 1982, p. 240, canto III, vv. 1880-1881.

52 Rafael Alarcón Sierra, El mal poema, p. 112.

53 Como es sabido, por esa leyenda el pelícano es figura alegórica de Cristo y asoma con frecuencia en la iconografía de la Crucifixión.

54 Alfred de Musset, Poésies, París, Nelson, 1933, p. 186.

55 Enrique Morente lo grabó y ahora lo canta su hija Soleá con Los Evangelistas (2013). 56 "En mil cuatrocientos y cincuenta y seis, / yo, François Villon, siendo bachiller, / después de pensar reposadamente" ("Legado", estrofa I). Véase François Villon, $o p$. cit., p. 35. 
diente"). Como en "Prólogo-epílogo", se recapitula desde un presente, decadencia de la decadencia, aunque sin confesar nada nunca de modo directo:

de tanta canallería harto estar un poco debo, ya estoy malo, y ya no bebo lo que han dicho que bebía ${ }^{57}$.

Igual que en el poema anterior, la conjunción causal marca un cambio en la faena del poema:

\section{Porque ya}

Una cosa es la poesía

Y otra cosa lo que está

Grabado en el alma mía.

Como si se volviese ilegible e imposible un verso como "Escrito está en mi alma vuestro gesto". Y hay más:

Grabado, lugar común.

Alma, palabra gastada.

Mía... No sabemos nada.

Todo es conforme y según.

Hay que ceder la palabra a Dámaso Alonso:

El efecto de hundimiento se ha conseguido expresando una especie de desilusión de segundo grado: desilusión de la poesía, primero; pero, luego, desilusión, de la expresión conceptual e idiomática de esa desilusión. Y para último verso, un tópico del lenguaje hablado ${ }^{58}$.

Quizá ese máximo de artificio acaba alejándose de la literatura, para que sin esconder ninguna carta, sin pretender naturalidad alguna, aparezca

57 José Zorrilla: "Yo soy viejo y ya no valgo / lo que dicen que valía”. Véase Rafael Alarcón Sierra, El mal poema, p. 119.

58 Dámaso Alonso, op. cit., p. 567. 
lo que veinte años después anunciaba García Lorca: "Pero si alguien tiene por la noche exceso de musgo en las sienes / Abrid los escotillones para que vea bajo la luna / las copas falsas, el veneno y la calavera de los teatros" 59 . Ahora bien, por ese camino de la paradoja seguimos sintiendo, fascinados, que es en el mal poema donde late la vida.

59 “Ciudad sin sueño". Véase Federico García Lorca, Poeta en Nueva York, ed. Andrew Anderson, Barcelona, Galaxia Gutenberg-Círculo de Lectores, 2013, p. 205. 